\title{
Opening up the West: An examination of four core questions on China's "Western development" campaign
}

\author{
T. L. Ringpapontsang \\ School of Economics, College of Business and Economics, The Australian National University, Acton \\ ACT 0200, Canberra, Australia
}

The widespread unrest across the Tibetan plateau and events in Xinjiang earlier in 2008 turned international focus directly on China's west region. The overriding policy initiative that is pivotal in understanding the current dynamics of the region is the Chinese government's Campaign to "Open Up the West". Grounded on an awareness of the unique complexities of the region, this essay examines the campaign through the guidance of four core questions that are critical to any understanding of the issue: Why did the Chinese government introduce the Campaign to Open Up the West? What kinds of policy measures are being implemented? How likely is policy to succeed in reducing and reversing the rise in regional inequalities? What are the major obstacles to success?

The campaign to Open Up the West is a multifaceted drive representing economic, environmental and political agendas. It has manifested primarily as an all-out push for rapid growth through enormous subsidies and subsidised investments via Chinese corporations based mostly outside the region; an open immigration policy that facilitates the movement of Chinese from other areas into the region, drawn by the state induced boom; and an absence of protection of the employment of the local population despite acute educational lags and a severe undersupply of education infrastructure relative to the rest of China. Contrary to conventional expectation, these "development" policies and the associated rapid growth have in fact been reinforcing the underlying political and social tensions through the marginalisation of local populations which ultimately revealed themselves in the form of social unrest and resistance.

\section{INTRODUCTION}

The events in Xinjiang and the widespread uprising by tens of thousands of Tibetans across the Tibetan plateau engulfing regions in five provinces of the People's Republic of China (PRC) earlier in 2008 - the year of the Beijing Olympic Gamesturned international focus directly on China's west region. The events that unfolded brought to the fore the complexities of the territory, shattering the myth of the region being just another area of China albeit with the added colour of happy and grateful minorities. Indeed, the western region of what is now the PRC is very different from her eastern regions geographically, historically, ethnically and politically. The stark dissimilarity between the Uigurs living at the edges of the Taklamakan and Kumtag deserts in the Tarim Basin of Xinjiang and the Tibetans of the grassy plains of the plateau highlands and at the foothills of the great Himalayas, in comparison to the habitants of coastal cities such as Shanghai and the agricultural fields of eastern China highlight these differences. Moreover, until quite recent times many of these areas were almost solely occupied by non Chinese peoples with their own sense of distinct identity, and in the case of the
Tibetans, their own sense of national identity ${ }^{1}$ coupled with their own Lhasa-based government and army. $^{2}$ Any analysis of the Chinese government's policy towards the west region must be grounded on an informed awareness of this context.

The overriding policy initiative that is pivotal in understanding the current dynamics of the region is the Chinese government's "Western Development" Strategy, also known as the Campaign to "Open Up the West" (xibu da kaifa $)^{3}$. This campaign is a multifaceted drive representing economic, environmental and political agendas. In its most lustrous emanation, it has manifested as an all-out push for rapid growth through enormous subsidies and subsidised investments via Chinese corporations based mostly outside the region; an open immigration policy that facilitates the movement of Chinese from other areas into the region, drawn by the subsidy induced boom; an absence of protection of the employment of the local population despite acute educational lags and a severe undersupply of

\footnotetext{
${ }^{1}$ Tsering (2004)

${ }^{2}$ Laird (2006)

${ }^{3}$ Goodman (2004a)
} 


\begin{tabular}{lrrr}
\hline $\begin{array}{l}\text { Mineral, Water, and } \\
\text { Hydropower }\end{array}$ & Reserves (\%) Land Type & Area (\%) \\
\hline & & & \\
Potassium & 97 & Unused & 79.6 \\
Nickel & 62 & Pastoral & 72.3 \\
Natural gas & 58 & Water surface & 39.0 \\
Platinum & 57 & Forest & 38.3 \\
Coal & 30 & Cultivated & 28.6 \\
Petroleum & 23 & Transportation & 24.3 \\
Underground water & 12.5 & Gardens & 23.3 \\
Hydropower potential & 80.3 & Residential, industrial, and mining & 22.7 \\
\hline
\end{tabular}

Table 1: Natural Resources in the Western Region as \% of national total. (Lai, H. H. China's Western

Development Program: Its Rationale, Implementation and Prospects, Modern China, 2002; 28; 432)

education infrastructure relative to the rest of China; and an assimilationist agenda within education policy. Contrary to conventional expectation, these "development" policies and the associated rapid growth have in fact been reinforcing the underlying political and social tensions through the marginalisation of local populations which ultimately revealed themselves in the form of resistance and social unrest. ${ }^{4}$

This essay provides an examination of the campaign through the guidance of four core questions which are critical to any understanding of the issue: Why did the Chinese government introduce the Campaign to Open Up the West? What kinds of policy measures are being implemented? How likely is policy to succeed in reducing and reversing the rise in regional inequalities? What are the major obstacles to success?

Since the formation of the People's Republic of China in 1949 and the subsequent annexation of territories to form what is now the western region of the PRC, this region has consistently lagged behind the eastern regions of China in almost every measure of economic development and social welfare. During this period, the lag of the western region has been preserved and aggravated by the ultimate failure of Mao Tse-Tung's Interior Development Strategy due to its contradictory policies, compounded by Deng Xiaoping's explicit economic favouritism towards the eastern coastal regions which began with the open door policy in 1979. Through the Campaign to Open Up the West, the subsequent leaders Jiang Zemin and $\mathrm{Hu}$ Jintao, may be viewed as fulfilling Deng's vision of developing the west after the

\footnotetext{
${ }^{4}$ Fischer (2008)
}

development of the east had gained momentum. The policy shift occurred vaguely during the Eighth Five-year plan (1991-95) and became more explicit during the Ninth Five-year plan (1996-2000). ${ }^{5}$

\section{WHY THE CHINESE GOVERNMENT INTRODUCED THE CAMPAIGN TO OPEN UP THE WEST}

The most evident economic motive behind the Campaign to Open Up the West has been the rising level of regional inequality between the eastern and western regions. In 1952 average per capita GDP in east China was 1.3 and 1.7 times higher than that in the centre and west respectively. These ratios had increased to 1.9 and 2.5 by 2000 . Provincial per capita GDP in 2002 ranged from 6,093 yaun in Gansu in the west to 40,648 yuan in the coastal municipality of Shanghai. ${ }^{6}$ This high and rising level of inter-regional economic disparity is of concern to the Beijing leadership not only because of the inherent inequities it represents but also because of this inequality's socio-political implications including the potential for widespread disenchantment in the region with the national leadership of the Chinese Communist Party.

This concern has been intensified with the onset of China's WTO membership and the apprehension that the long isolated officials and population of the western regions who are more accustomed to the command economy structure and state owned enterprises which have tended to dominate the western region's industrial output will be hard

\footnotetext{
${ }^{5}$ This paragraph draws on Golley (2004).

${ }^{6}$ Golley (2004)
} 
pressed to compete against internationally competitive foreign firms.

Some also view the development of the western regions as complementary to the development of the eastern regions due to the west's wealth in natural resources as illustrated in the Table 1. They believe that further exploitation of these resources will not only bring growth to the west but will also help to satisfy the east's seemingly voracious appetite for such resources as its rapid economic growth continues. ${ }^{7}$ However, such a simplistic analysis belies the true complexity of the issue. In fact, there is the possibility that the western region is becoming subject to the 'resource curse' where forward thinking industrial policies are neglected while resource-extraction takes centre-stage, primarily for the benefit of other regions. ${ }^{8}$ Another reason for the inter-regional complementarity concept is based on the idea that the western region, where the rate of household consumption of manufactured goods is still much lower than in the coastal regions, represents a large untapped potential source of domestic consumption demand for the manufactures from other parts of China

Another aspect of the Campaign to Open Up the West according to official Chinese government sources is management of environmental and ecological issues. ${ }^{9}$ With an estimated $70 \%$ of China's urban population exposed to air pollution, 700 million Chinese having to consume water polluted with human and animal waste ${ }^{10}$ while hundreds of cities are short of water, and with 3,400 square kilometres of land turning into desert every year, ${ }^{11}$ attention to these issues is urgently due.

A further principal reason behind the recent introduction of the Campaign to Open Up the West in its current form appears to be aimed at ensuring social and political stability in the non-Han-Chinese areas of the PRC. Indeed, the current campaign by Beijing in the western regions has much in common with colonial experience elsewhere in the world, ${ }^{12}$ highlighted by the efforts at promoting the 'Peacock

\footnotetext{
${ }^{7}$ O’Donnell (2000)

${ }^{8}$ Golley (2007)

${ }^{9}$ Overall Plan of Western Region Development During the Tenth Five-Year Plan Period (1 and 2), accessed at $<$ http://www.chinawest.gov.cn/english/index.htm>, [on 5/10/2005].

${ }^{10}$ O’Donnell (2000)

${ }^{11} \mathrm{Li}(2003)$

${ }^{12}$ Goodman (2004a)
}

flying to the west' phenomenon. In other words, concerted government efforts at immigration of the majority Han Chinese who constitute over 1.2 billion of China's national population, into those regions. Now, many of the actual peoples of these regions are becoming shrinking minorities in their historical homelands and this undertaking seems likely to be accelerated further with explicit official policy intentions to "lower the natural growth rate of population significantly" ${ }^{13}$ in those regions while simultaneously introducing policies to further facilitate the movement of people from other regions into these areas supported by the lure of the government induced boom. Indeed, Li Dezhu, who until March 2008 was the head of the Ethnic Affairs Commission, a state body responsible for relations between the central government and ethnic minorities, is reported to have explicitly stated that the problem of minorities would be "definitely solved" through mass migration of Chinese into minority areas. ${ }^{14}$

The 2001 commencement of US military operations in bordering Afghanistan is also seen as having added further urgency to the perceived need for western development. This has meant that strategically, some in China feel a real need to further consolidate its hold on the west, both economically and politically. ${ }^{15}$

\section{TYPES OF POLICY MEASURES BEING IMPLEMENTED}

From a theoretical perspective on development based on Myrdal's thesis there are (at least) three types of policy options. ${ }^{16}$ They are the 'Laissez Faire-neoclassical' approach to regional policy where the government focuses on fundamental policies that aim to allow the private sector to operate effectively and efficiently, the 'development state' approach where state intervention is prevalent, and the 'market enhancing' approach where the government complements private sector and marketbased coordination, rather than substituting for it. The market enhancing approach may be the most effective ${ }^{17}$ and viable policy choice. Moreover, this approach has proved successful in China in the past

\footnotetext{
${ }^{13}$ Overall Plan of Western Region Development During the Tenth Five-Year Plan Period (1), op. cit.

${ }^{14}$ Sheridan (2008)

${ }^{15}$ Bedeski (2004)

${ }^{16}$ Golley (2004)

17 ibid.
} 
as demonstrated by Deng Xiaoping's experiment in the east. However, the extensive involvement by the state in the many facets of the current campaign suggests that perhaps the central Chinese government is pursuing a more 'development state' type approach. Indeed in government material there seems to be much emphasis on the need to "bring into play regional comparative advantages" $" 18$ and it appears that this is to be implemented by the central government deciding which provinces and administratively-called autonomous regions are to specialise in what - which effectively translates into trying to 'pick winners'.

The central and local governments have implemented a number of specific explicit policies as part of the Campaign to Open Up the West. These policies include the objectives of promoting investment in the region, managing the region's fragile ecological balance and strengthening the economic association between eastern China and the central and western regions. As part of the policy to promote investment in the western region, favourable conditions for foreign investors in terms of the legal environment, approval procedures and tax incentives have been set up. ${ }^{19}$ The sectors in which foreigners may invest have been expanded and the joint development of natural resources is being encouraged. Concurrently, policies to boost the fiscal subsidies for regional governments and regional investment have been implemented.

There has also been an easing of the family register transfer policy in order to facilitate the movement of human resources to the west. This allows the free movement of people into the west region without transference of their family register, thus reducing the risks associated with relocating by allowing migrants to maintain their current residency status and not forego the welfare and social privileges accorded by the government to legal residents should they choose to return. A myriad of other policies were announced including the further development of general infrastructure in the region as well as the implementation of what has been called the "Five Mega-Projects"20. A further policy which the central government has attempted to utilise is what is called the 'Coastal-interior Cooperation' - direct aid from rich coastal provinces to poorer western areas. These have been called

\footnotetext{
${ }^{18}$ Overall Plan of Western Region Development During the Tenth Five-Year Plan Period (1 and 2), op. cit.

${ }^{20}$ Lin and Liu (2004)
}

'mutually beneficial cooperation' although there is some evidence of central government armtwisting. ${ }^{21}$

Likelihood of policy in succeeding to reduce and reverse the rise in regional inequalities

Some analysts have described the Open Up the West Campaign as 'soft policy' ${ }^{22}$ which is long-winded yet devoid of clarity and detail on how the objectives will be achieved. It seems likely that any impact of the campaign on reducing regional inequalities will be diminished by the number of other environmental, political and racial agendas behind the campaign.

Of the ' 5 Mega Projects', only the Qinghai-Tibet railway project which was completed in 2006 is entirely in the western region. Even with this project, as Lin Ling and Liu Shiqing note, a priority is the promotion of national unity, to consolidate the parameters of China's frontiers, as well as national defence $^{23}$ rather than solely economic development. Others also see this particular project as a double purposed venture which is of enormous threat to the unique culture and identity of Tibetans on the Tibetan plateau.

Although state budgetary appropriations to the western region has increased, Chinese and foreign private investors have not followed the government funds into these areas and thus growth does not appear likely to become self-sustaining. Indeed, foreign investment in the western region actually fell from $9 \%$ of the national total in 1996 to $6 \%$ in 2002. ${ }^{24}$ Furthermore, empirical evidence thus far suggests that there has been no reduction in the level of regional inequality since the campaign's inception.

The central government's provision of a series of preferential policies and increased government investment in large-scale infrastructure and basic industry may help in laying a solid foundation for future economic growth driven by the private sector and therefore perhaps gradually reduce the rise in the level of regional inequalities in a sustained manner. Thus far, economic growth in much of the region has been heavily dependent on the state sector. This level of dependence is highlighted by the Tibet Autonomous Region (TAR) where $90 \%$ of the economy was government-driven in 2003. ${ }^{25}$

\footnotetext{
${ }^{21}$ Golley (2004)

${ }^{22}$ ibid.

${ }^{23}$ Lin and Liu (2004)

${ }^{24}$ Jane Golley (2004)

${ }^{25}$ Kyodo News International (2003)
} 
However, with limitations on government expenditure, there is no guarantee that the current level of support will be sustained or that it is indeed sustainable. Given the colossal dimensions of the regional inequalities problem the adequateness of even the current level of fiscal spending in the development of the western region in making the Open Up the West Campaign a success is questionable.

The nature of government expenditure in the western regions has also been a factor in reducing the effectiveness of government spending in generating self-sustaining economic development. For example, official 2003 statistics revealed that expenditure on local government administration in TAR was growing at $46 \%$ per year, ranking as the region's fastest growing industry. ${ }^{26}$ Such disproportionate growth of the local government administration may reflect a focus on controlling the region rather than development. This transpires in the form of a multitude of initiatives such as the institution of the "Work Teams" in monasteries and nunneries all across Tibet that have been implementing the infamous "Patriotic Re-education" campaigns.

In the area of foreign investment, little has been achieved despite efforts to promote the region to foreign investors through various trade fairs and forums. It is doubtful whether the new preferential policies granted to the western region, such as the $15 \%$ corporate tax rate, will have the desired effects because many of the policies are not really more favourable than the ones already granted in the coastal regions. Furthermore, foreign investment is unlikely to freely flow into a region characterised by social tension, rampant corruption, and an entrenched lack of enforcement of and respect for the basic conditions necessary for the functioning of the market system such as property rights and clearly defined contractual obligations.

If the current largely state-driven economic growth is feasibly sustained over the long run, it may succeed in reducing regional inequalities, at least on an aggregated level. Indeed, it is clear that for those who fit the requisite criteria, namely those with Chinese language fluency, good connections to economic and political centers in other regions of China, and who thrive in Chinese work cultures profit considerably from the subsidy and subsidised

\footnotetext{
${ }^{26}$ ibid.
}

investment induced growth. ${ }^{27}$ Moreover, with the continuation of the rapid economic growth in the eastern region where industrial agglomeration following Myrdal's theoretical notion of 'circular and cumulative causation' has taken place, theoretically there is the future potential for 'spread effects' to take place, in other words, for the trickle down of the eastern development into other regions. ${ }^{28}$ Practically, when and how this might actually happen is another matter.

Furthermore, before drawing hasty welfare conclusions based on any reported economic growth in the region, it must be noted that statistical indicators of aggregated data often say very little about the distribution of welfare changes and interethnic inequalities, or the people's concerns for the survival of their cultural heritage or their freedom to be in control of their lives. In fact, most in the minority populations in these regions have hardly derived any even purely economic benefits from the rapid growth. Thus, in some of these regions, the current development strategies have led to rapidly rising inequalities which are much higher than even that observed anywhere else in China. Additionally, these ethnic inequalities are occurring within urban areas confirming that ethnic inequalities are not merely a reflection of rural poverty. ${ }^{29}$

Indeed for some minority populations even the Chinese language is alien. Yet they find themselves in an economic and social environment where their native languages are being driven to disuse while the Chinese language and culture is rapidly becoming the only medium of survival. Coupled with the abandonment of most previously-existing protections of local labour even in the 'autonomous regions', minority populations find themselves in a labour market where they must compete in a sinicised environment with a rapid influx of Chinese migrants from other regions for whom Chinese is their native language and who have often had access to better education. In fact, minority populations in the west region are among the most poorly educated in the whole country. For example, only $15 \%$ of the Tibetan population in the region have some form of secondary education and the accompanying degree of fluency in Chinese. ${ }^{30}$ Moreover, the education provided in many minority areas has been a distorted form of education where the priority appears to be

\footnotetext{
${ }^{27}$ Fischer (2008)

${ }^{28}$ Golley (2004)

${ }^{29}$ Fischer (2008)

${ }^{30}$ Fischer (2008)
} 
ensuring subordination rather than intellectual and economic advancement. The type of mentality among policy makers and enforcers that is responsible for such distortions is typified by Chen Kuiyuan, who in 1994 while he was the TAR Regional Party Secretary is reported to have said at a conference on education that the success of education "...does not lie in the number of diplomas issued... It lies, in the final analysis, in whether our graduating students are opposed to or turn their hearts to the Dalai clique and in whether they are loyal to or do not care about our great motherland..."”1

\section{OBSTACLES TO SUCCESS}

A major obstacle to the success of policy in reducing and reversing the rise in regional inequalities may prove to be fact that the attempted coverage of the campaign is too broad and not targeted enough. The extreme geographical aspects of the west which features mountains and deserts also presents challenges. The heavy dependence on direct government fiscal appropriations coupled with the government's own financial constraints as well as rampant corruption and misallocation of state funds forms another major hurdle. For example, in the TAR subsidies and subsidised investments have been incredibly inefficient, characterised by a 'negative multiplier effect' on growth; with only 0.5 yuan of GDP increase for every one yuan of increased subsidies and investment in 2001, and the situation had barely improved by $2005 .^{32}$

The constant neglect of real objective education in the western region has also resulted in poor human resources. Despite the Open Up the West Campaign associated drive for ecological and environmental management, much of the western region's ecology remains in a dire situation, and the promotion of mass in-migration from other parts of China may once again end in ecological and perhaps human disaster, repeating the catastrophe in Qinghai during the massive in-migration drive during the $1950 \mathrm{~s}^{33}$

\footnotetext{
${ }^{31}$ Chen Kuiyuan, The Regional Party Secretary, speaking at the $5^{\text {th }}$ TAR Conference on Education, 26 October 1994.

${ }^{32}$ Fischer (2007)

${ }^{33}$ Goodman (2004b)
}

There is perhaps also a lack of local knowledge amongst policy makers in Beijing who tend to take too much of a top-down totalitarian approach to problems rather than taking an approach to problem solving where the welfare of the actual people on the ground is at its core. Particularly, in minority areas which are often ruled by non-minority officials even at the local level, there appears to be a complete lack of understanding of and empathy with the aspirations and concerns of the minority population and their distinct cultural values and way of life. If government policies do not address their concerns and lead to an improvement in their welfare but instead to their greater marginalisation resistance to government control and policies will continue.

Indeed, this widespread and acute disaffection with current government policies including elements of the Campaign to Open Up the West is embodied in the events on the Tibetan plateau and Xinjiang earlier in 2008, and this sentiment will only be aggravated if the only government response to expressions of the ethnic populations' dissatisfaction is brutal crackdown and intensification of attacks on their distinct identity through population inmigration and tighter government control of all aspects of life. Moreover, their sense of belonging to the Chinese nation is not aided when the overwhelming response to their expressions of discontentment by the masses of their compatriots from the majority ethnicity, whether on the streets of towns and cities or forums on the internet, is to crush and destroy their entire people.

Such disaffection and the resulting social division and resistance do not bode well for the development of the west region nor for the unity and stability of the whole of the PRC upon which the current rapid economic growth is founded. True lasting stability cannot happen under the threat of force from Beijing. But it can occur in a society where central government policies reflect the rights and interests of all the nationalities and peoples who together make up the nation, not just the interests of a subdivision of the population. Therefore, the implementation of policies which are based on economic rationalism that enhances the market, empowers the population through objective education and at the same time respects the dignity and addresses the concerns of the different sectors of the People's Republic of China's society including those of the minorities will be more effective and more universally embraced. Such policies will have a greater chance of not only reducing regional economic disparities but also in reducing ethnic 
inequalities within the west region and in maintaining the successes over the long run without continued resistance. Then the peoples of the west region will be better able to contribute to the development of their region and the nation at large, sharing in a common sense of belonging and in the fruits of common prosperity.

\section{ACKNOWLEDGEMENTS}

I am grateful to Dr. Jane Golley for her most helpful comments and suggestions

\section{REFERENCES}

Bedeski, R. (2004), "Western China: Human Security and National Security", in Ding Lu and William A. W. Neilson (Editors) China's West Region Development: Domestic Strategies and Global Implications, World Scientific.

Fischer, A. M. (2007), "Perversities of Extreme Dependence and Unequal Growth in the TAR", Tibet Watch Special Report August 2007, Tibet Watch. Fischer, A. M. (2008), "Reaping Tibet's Whirlwind", Far Eastern Economic Review, 20 March 2008.

Golley, J. (2004), "Regional Policy and Economic Growth", Chapter 9 in Ross Garnaut and Ligang Song (Editors) China: Is Rapid Growth Sustainable?, Asia Pacific Press.

Golley, J. (2007), The Dynamics of Chinese Regional Development: Market Nature, State Nurture, Edward Elgar Publishing.

Goodman, D.S.G. (2004), "The Campaign to 'Open Up the West': National, Provincial-level and Local Perspectives", The China Quarterly, Special Issues New Series, No. 5, June, 2004.

Goodman, D.S.G. (2004), “Qinghai and the Emergence of the West: Nationalities, Communal Interaction and National Integration", The China Quarterly, Special Issues New Series, No. 5, June, 2004.

Kyodo News International, "Government administration leads Tibet's economy”, 22 December 2003.
Lai, H. H. (2002), “China’s Western Development Program: Its Rationale, Implementation and Prospects", Modern China, Volume 28, No. 4, 2002.

Laird, T. (2006), The Story of Tibet-Conversations with the Dalai Lama, Grove Press.

Lin, L. and S. Liu (2004), "Measuring the Impact of the 'Five Mega-Projects', in Ding Lu and William A. W. Neilson (Editors) China's West Region Development: Domestic Strategies and Global Implications, World Scientific.

Sheridan, M. (2008), "Ethnic repression in Tibet masterminded by faceless Chinese trio", Times Online, 23 March 2008.

O’Donnell, L. (2000), “Tibet Pours Troubled Water on Asia", The Australian, 19 September 2000.

Overall Plan of Western Region Development During the Tenth Five-Year Plan Period (1 and 2), accessed at $<$ http://www.chinawest.gov.cn/english/index.htm $>$, [on $5 / 10 / 2005]$.

Tsering, C.P. (2004), The Nature of All Things: The life story of a Tibetan in exile, Lothian.

Li, Z. (2003), "Energy and Environmental Problems behind China's High Economic Growth", Forum on Research Works, The Institute of Energy Economics, Japan. 